\title{
The Research on Multi-Dimensional Open Teaching Model Based on New
}

\author{
Media \\ Liu Qing \\ Network information center \\ Qilu University of Technology \\ JiNan China \\ e-mail:liuqing@qlu.edu.cn
}

\begin{abstract}
KeyWords: New media, multi dimensional open teaching model, autonomous learning, cooperative learning, open teaching environment
\end{abstract}

\begin{abstract}
With the rise of new media and the development of educational technology,the combination of new media and classroom teaching has gradually become the focus of teaching research.According to the characteristics of new media,this paper analyzed its influence on the teaching mode of higher education,and then expounded the core idea of multi-dimensional open teaching mode.

In recent years, with the progress of science and social economy, the new media is showing a rapid development trend.The $36^{\text {th }}$ China Internet network development state statistic reportwhich issued by CNNIC(China Internet Network Information Center) showed that,as of June 2015,there are 668 million Internet users in China, among them the mobile phone users reached 594 million.With the increase of the mobile phone screen, as well as the application of experience, mobile phones have become the preferred tool for Internet users,Blog, podcast, microblogging, micro channel users and other diverse media forms continue to emerge.

The traditional media is one point to multiple points communication, while the new media is multiple points to multiple points ,the new media has breaked the boundary between the sender and receiver ,because of its interactivity and cross time and space characteristics, the new media in the teaching can establish really contact with the student.In addition, the use of the media habits of college students will undoubtedly have an impact on their learning and life.It is important to release of College Students' enthusiasm for the new media, and then applied to their course learning.
\end{abstract}

\section{The influence of new media on College Classroom Teaching}

\section{Teaching information becomes more open}

The information environment of the traditional teaching has obvious "center" characteristic,as the center of the whole teaching environment,the teacher have a great majority of information sources,the information is transmitted to students in a divergent way,and the teacher can control the classabsolutely.[1]In this case, the students got the information mainly by the one-way transmission of the teacher, so the information environment was relatively closed, the information resources presented a serious imbalance between teachers and students, and it will further hinder the question ability and innovation ability of students.

With the development of new media,students had more and more ways to get information.With the rapid acceptance of new media and the use of high frequency, college students can find the vast amount of information on the Internet, and select a large number of information related to their learning,the imbalance of information resources between teachers and students is broken.Students have more autonomy in the learning process, and the teacher's role will gradually fade,the teacher became the student's study assistant, and their intention, ideas, opinions, through the technical media 
form to be reflected,all of these were presented in the form of media.Although students got more and more information through a variety of new media,but these information have valuable or not also need the students to judge.Therefore, it is an important ability for students to question and criticize the received information according to certain standards.

Secondly, the teaching process became more flexible.

The teacher is the core in the traditional teaching, as the starting point of the teaching process the teacher design all the contents,all the teaching process is relatively closed,The teachers and students are in the two ends of teaching process, the information was not really formed the dynamic circulation between them, besides, they also lack of information communication. The teachers can use WeChat, QQ and other new media forms, because it is more convenient to get information for students,using task-driven method to mobilize students' learning initiative.In the classroom instruction, the traditional one-way communication transformed into the two-way communication which between teachers and students.

\section{Teaching evaluation became more convenient and accurate}

In the traditional teaching process, the test of teaching effect only relying on the after-school homework,quizzes and other wayswhich can only be carried out after the class.Due to the impact of other objective factors, such as: environmental factors and personal factors,etc, the accuracy of the evaluation results also declined.

With the popularity of new media,the scope and speed of information search have greatly improved, and the view of the students also became more open.Teachers can use the new media to test the effect of teaching in the classroom, for example,using WeChat platform to check objective questions by making a survey questionnaire,Students using mobile phone to answer the question at once in the class, and the teacher can check the student's answer by the mobile phone, so as to adjust the teaching strategy in time.

With the rapid development of new media technology, the application of Computer Assisted Instruction tools and auxiliary teaching media in the teaching has become more and more extensive and mature,the new media assisted teaching is the best way to improve the teaching efficiency by stimulating human's vision, hearing and other organs.It could be further increase the students learning interest and get better teaching results, which combining a variety of new media in the teaching process.

\section{The core of multi- dimensional open teaching}

Multi dimension refers to a complete teaching process,it is an organic whole, which is composed of the pre class preparation, classroom teaching, students' self-study (including classroom discussions, homework exercises, etc.) and social practice.It requires that the fully arouse the enthusiasm of teachers and students, In addition to the use of teaching equipment, books and materials, but also make full use of all kinds of new media,the monotonous activities which teachers in the classroom teaching materials would be changed into lively teaching style with rich contents.Multi-dimensional open teaching method is an effective way to give full play to teachers' leading role and students' main body status.Its core idea is to be independent, cooperative and openning, which is the reform and transcendence of traditional teaching.Through the implementation of multidimensional teaching method, not only can make the classroom full of vigor and vitality,but also to extend the teaching activities to the pre class and after class.

\section{Strengthen cooperative learning ability}

In the new media communication environment, teachers and students, students and students, teachers and teachers through new media communication technology, to build up the cooperative learning ability which can work across time and space.In addition, there is another kind of cooperation between students and huge amounts of information.Students can master the learning contents more deeply when they on the same topic to discuss, exchange and cooperate with each other.Through the new media, collaborative learning range is greater, the way more flexible and diverse, synchronous or asynchronous interaction to share their learning experiences and learning resources to promote the cultivation of students' cooperative ability. 
Teaching cooperation between teachers and students are no longer limited to face-to-face synchronous interaction, also can beyond the limitations of time and spaceThe boundaries between the inside and outside of the campus and classroom are no longer clear.The limitation has been compensated which in the traditional classroom interaction teaching,the interaction between teachers and students can achieve anytime and anywhere.[2] Under the network environment, students can use the new media to obtain abundant learning resources from the Internet, new media has become an important tool for students to learn.

\section{Strengthen autonomous learning ability}

Teachers can use a variety of media to guide teaching activities, and the new media in the classroom teaching should also emphasize the construction of knowledge, constructivist learning theory emphasizes that the new knowledge and skills of learning should be constructed from the old knowledge, and teachers are playing the role of guide.

Teachers can use the communication tools such as mobile phone text messages and WeChat for the notice before class, and assist students to review after class.The new media assisted instruction which achieve the individualized and personalized teaching under the background of collective teaching,could help students set their own pace and master their learning rhythm.Mainwhile, also arouse students' learning initiative and enthusiasm,to cultivate students' innovative spirit and practical ability, and make full use of their learning experience to gain the new knowledge. It is equal between teachers and students, which emphasizes the students' independent thinking, and guide its participation in the cooperation and communication.The characteristics of the concealment of the new media, make every student have equal communication opportunity, student's discourse power could be expanded in the new media support, at the same time their enthusiasm and initiative also very high.Using the technology feature of new media, teachers can set up the theme of the key words or group discussion,on the same issue, students can express their views useing a weblog platform or mobile media,all kinds of views are presented on the platform, to produce more ideas through communication,forming a teaching method which the contents constructed both by the teachers and students[3].The transfer of information in the multi-dimensional teaching method is comprehensive.Students can take full use of their various senses to participate in teaching activities, it not only can enhance the interactive of teaching process , but also help to the acquisition and maintenance of knowledge.To promote the development of the students' abilities,and comprehensively improvetheir quality as well.[4]

Building an open learning environment

"Open teaching" means that in the open environment,taking the problem as the premise, the teacher plays a role of guidance, teachers and students communicate in many ways, promotes the good thought quality the formation, cultivate students' innovation spirit and ability. The open learning environment includes the opening of the learning resources, the opening of the teaching space and the opening of the learning thinking.

First of all,the opening of learning resources, mainly refers to the students to make full use of network resources besides textbook knowledge.New media assisted instruction can set up the key words in advance, so that students to collect materials in the mass of information,and to communicate with the teacher or the students in time, which can make the students thinking and improving the incomplete contents.In the teaching process,the teachers are mainly to teach students how to learn and to stimulate their curiosity.

Secondly, the opening of the teaching space and time. While new media can be combined in the course of in-class and after-class, with more flexibility in time and space.For example, the teacher can leave a question to the students at the end of the lecture, which is more difficult than the general problem.And arrange the answer time,which can be a fixed time or random time.Teachers use answering questions with students after class.Learning activities beyond the fixed place and time, so that students make full use of fragmented time in their daily lives.[5]

Thirdly,the opening of the learning thinking.To cultivate students' ability to analyze problems, through the classroom questioning and homework.Paying particular attention to the open questions, the process of solving the open problem is a new thinking training.[6]The new media is not only a teaching tool, but also has the role of teachers and the learning partners in the multi-dimensional teaching method. 


\section{What should be paid attention to in the opening teaching method based on the new media?}

Although traditional teaching cannot be compared with the advantages of open teaching method, but this does not mean that it can replace the traditional classroom teaching method.

The open teaching method which based on the new media is a useful supplement to the traditional teaching .

In new media assisted instruction,the traditional teaching mode in the classroom is essential, and it is very important to combined with the book knowledge and multimedia projection 、 blackboard writing in the teaching of basic knowledge.students must be establish the initial impression in the conceptual knowledge of some of the courses, in order to further expand their learning in the new media teaching.

Using task driven approach to the teaching

In the course of teaching, "task driven" teaching method is required to complete each task which implied the teaching contents, and in the process of solving the task, the students themselves continue to raise questions and then solve them.Teachercould give students the right amount of tasks, which sudents can be put into practiceand get fun from it.

"Task driven" teaching method has formed the basic characteristics of "taking the task as the main line, the teacher as the leading and the students as the main body", so the teacher's role must be transformed.The teacher's role transformation has a double meaning:One is from the teaching into the organization and guidance;two is the teacher from the platform to the students to communicate with them.This teaching method can help students to construct new knowledge, and if combined with teachers' Formative Evaluation and summative evaluation, the teacher can obtain good teaching effect as well.

\section{Open teaching should pay attention to the cultivation of students' media literacy}

In the information age,new media has played a powerful function and its negative role is increasingly apparent.How to use all kinds of new media to be a basic quality of modern college students.In the open teaching, teachers should constantly update the media concept, but also pay attention to the cultivation of students' media literacy, to guide students to set up the consciousness of media convergence, cross the use of various media to present teaching content and practice training, using new media to update professional knowledge.Only in this way can students understand the characteristics of different media forms, understand the rational use of media resources and constantly improve their knowledge system.

\section{The Conclusion}

Whether the old media or new media are not naturally applied to teaching,it must be through purposeful transformation to make it serve for the teaching.Open teaching method based on new media is not only the extension and supplement of the traditional teaching method,it also combined the classroom teaching v the scientific development and social development closely,and provides a wider space for innovation for teachers and students.At the same time, it also puts forward more challenges to the teaching of teachers, and we should actively adapt to the new media, and give full play to its advantages in teaching.

[1] Sun Yimin,Zhu Xinshun,"“The optimization and configuration of the teaching resources of the network platform in the new media environment”, Industry and Technology Forum, $19^{\text {th, }} 2014$

[2] Wang Lili,“Multiple media combination of interactive new media teaching under the network environment,New Media Studies,2015

[3] Zhou Hongchun, Liang Jing, "the reform of the teaching mode of the University under the new media environment",Chinese audio-visual education, $8^{\text {th }}$ 2013, pp.91-94

[4] Li Rong, Li Baiping, "multi dimensional teaching method in microwave and satellite communications (Teaching)","Journal of Wuhan University: Science Edition,S2,2012,pp 145-146. 
[5] Mi Zhiqiang, Hou Xiaomao,"The trial of three-dimensional teaching method build vocational school curriculum teaching of "computer assembly and maintenance”,Computer knowledge and technology,June,2007

[6] Yuan Lina Zan Haobo"The research on the reform of classroom teaching in Colleges and Universities under new media environment”, Science and technology communication, February 2014 